\title{
Delayed migration of a transfemorally implanted aortic bioprosthesis
}

\author{
Costin Radu, MD, ${ }^{\mathrm{a}}$ Richard Raffoul, MD, ${ }^{\mathrm{a}}$ Eric Brochet, $\mathrm{MD},{ }^{\mathrm{b}}$ and Dominique Himbert, MD, ${ }^{\mathrm{b}}$ Paris, France
}

Transcatheter aortic valve implantation has expanded the possibilities of treatment of aortic stenosis to patients considered at too high risk for aortic valve replacement. We report the delayed migration of a transfemorally implanted aortic bioprosthesis and discuss the potential causes of this complication.

\section{CLINICAL SUMMARY}

An 85-year-old-man with symptomatic aortic stenosis was referred for transcatheter aortic valve implantation. He had a history of diabetes, hypertension, peripheral vascular disease, and patent coronary artery bypass grafts. Transthoracic echocardiography (TTE) and transesophageal echocardiography revealed a moderately calcified tricuspid aortic valve with area of $0.6 \mathrm{~cm}^{2}$, mean gradient of $39 \mathrm{~mm} \mathrm{Hg}$, subvalvular nonobstructive septal hypertrophy measured at $16 \mathrm{~mm}$, pulmonary artery systolic pressure of $40 \mathrm{~mm} \mathrm{Hg}$, and left ventricular ejection fraction of $45 \%$. Aortic valve calcification score according to computed tomographic scan was 2980 Agatston units. The logistic EuroSCORE was $26 \%$, and the Society of Thoracic Surgeons Predicted Risk of Mortality was 9\%. Aortic annulus diameter was measured at $20 \mathrm{~mm}$ on TTE and transesophageal echocardiography and at $21.4 \times 26.1 \mathrm{~mm}$ on computed tomographic scan. Femoroiliac vessels were suitable for the transfemoral approach.

The procedure was performed under fluoroscopic guidance, as detailed previously elsewhere, with the patient under locoregional anesthesia. ${ }^{1,2}$ Briefly, after insertion of the closing device in the left common femoral artery (Prostar; Abbott Vascular, Santa Clara, Calif), retrograde crossing, and predilatation of the native valve, a 23-mm SapienXT prosthesis (Edwards Lifesciences Inc, Irvine, Calif) was positioned within the aortic valve and delivered by balloon inflation under rapid ventricular pacing. The prosthesis position after implantation was correct according to

\footnotetext{
From the Departments of Cardiovascular Surgery ${ }^{\mathrm{a}}$ and Cardiology, ${ }^{\mathrm{b}}$ Assistance Publique-Hôpitaux de Paris, Bichat-Claude Bernard Hospital, Paris, France.

Disclosures: D.H. is proctor for Edwards Lifesciences SA, Nyon, Switzerland, and Medtronic, Inc, Minneapolis, Minn (CoreValve). E.B. is proctor for Edwards Lifesciences SA, Nyon, Switzerland. The other authors have no conflict of interest to declare.

Received for publication March 25, 2011; revisions received Aug 22, 2011; accepted for publication Sept 15, 2011; available ahead of print Oct 13, 2011.

Address for reprints: Costin Radu, MD, Department of Cardiovascular Surgery, Assistance Publique-Hôpitaux de Paris (AP-HP), Bichat-Claude Bernard Hospital, 46 rue Henri Huchard, 75018 Paris, France (E-mail: costin.radu@bch.aphp.fr). J Thorac Cardiovasc Surg 2012;143:e1-3

$0022-5223 / \$ 36.00$

Copyright (C) 2012 by The American Association for Thoracic Surgery doi:10.1016/j.jtcvs.2011.09.014
}

fluoroscopy. TTE revealed a trace of paravalvular leakage (Figure 1). The patient was in stable condition, and after 24 hours in the intensive care unit, TTE revealed a mean gradient of $19 \mathrm{~mm} \mathrm{Hg}$, good left ventricular function, and no aortic regurgitation. Hypertension was well controlled with nicardipine hydrochloride (INN nicardipine) administered intravenously in the intensive care unit and with valsartan and furosemide thereafter. At postoperative day 5 , the predischarge TTE revealed that the prosthesis had migrated into the left ventricular outflow tract beneath the level of the native valve, which was functioning without aortic regurgitation (Figure 2). The condition was well tolerated hemodynamically, but the bioprosthesis was hindering the anterior leaflet of the mitral valve. Reoperation was decided by the medicosurgical team. Transesophageal echocardiography and surgical findings confirmed the TTE findings (Figure 2). The prosthesis was easily removed. The aortic annulus was measured with Hegar dilators at $24 \mathrm{~mm}$. The cusps were removed, and a 23-mm Epic (St Jude Medical, Inc, St Paul, Minn) bioprosthesis was implanted. The postoperative course was uneventful.

\section{DISCUSSION}

Late migration toward the left ventricle of 2 transapically implanted bioprosthesis in a single patient has been reported, but in that case the first valve may have been implanted in a slightly too ventricular position. ${ }^{3}$ In another report, a patient with a severely calcified aortic annulus and normally functioning bileaflet mechanical mitral prosthesis had late upward displacement of a transapically implanted aortic bioprosthesis. $^{4}$

In our case, migration of the bioprosthesis must have occurred late and gradually because there was no aortic regurgitation immediately after the implantation according to either angiography or TTE, and when patient left the intensive care unit the prosthesis was correctly positioned with no aortic regurgitation. The subvalvular septal hypertrophy could be incriminated for the postprocedural gradient. Moreover, it might have prevented further migration of the bioprosthesis in the left ventricular cavity. The most likely explanation for this migration might be the underestimation of the annular size by echocardiographic and computed tomographic measurements. The valve size was chosen in accordance with echocardiographic measurements, which is our preferred method, although we acknowledge that a gold standard does not exist. Undersizing may not be the only explanation, however, because there was no aortic regurgitation and the valve did not 


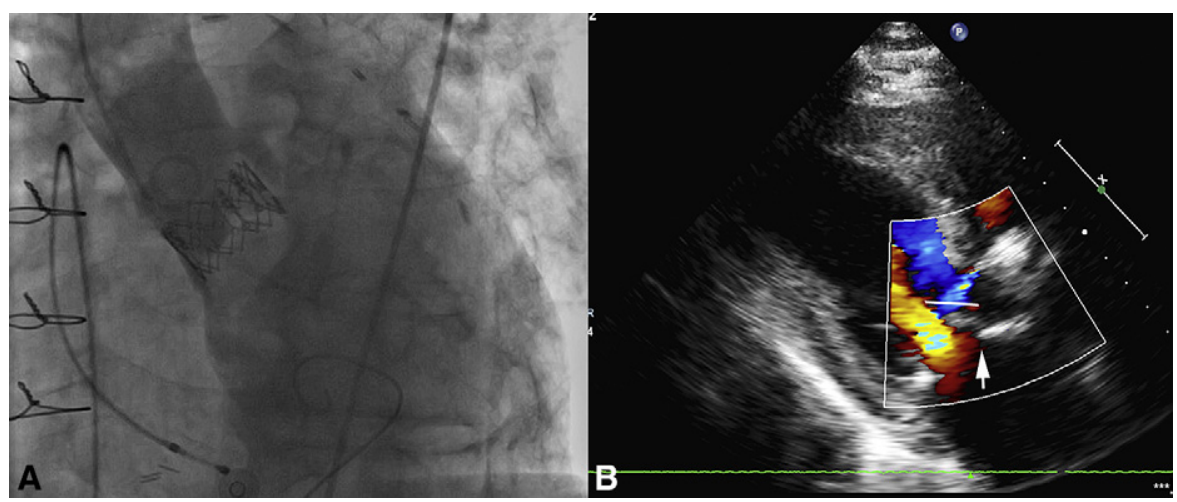

FIGURE 1. Aortography (A) and transthoracic echocardiography (B) at implantation showing correct positioning of the prosthesis and absence of significant aortic regurgitation. Arrow shows the inferior limit of the prosthesis; bar depicts the position of the anterior mitral leaflet.

migrate immediately. Moreover, a moderately calcified valve might provide less support for the bioprosthesis, because fixation of percutaneous valves occurs at the annulus and on the entire length of the calcified cusps. In our case, the aortic valve appeared only moderately calcified on echocardiography and fluoroscopy. The Agatston score was relatively high at 2980 units but was still in the moderate range for severe aortic stenosis. More oversizing might be considered in scarcely calcified valves but must be balanced against the risk of annular rupture.
Hypothetically, a CoreValve (Medtronic, Inc, Minneapolis, Minn) device might be more adapted in this situation, because it has a longer stent providing a longer area of fixation, but this has not been proved.

This complication emphasizes the importance of accurate measurement of the aortic annulus before transcatheter aortic valve implantation to avoid undersizing. The migration could have subsequently resulted in severe aortic regurgitation or lesions of the mitral valve. Interestingly, our patient was symptom free, which underlines the importance

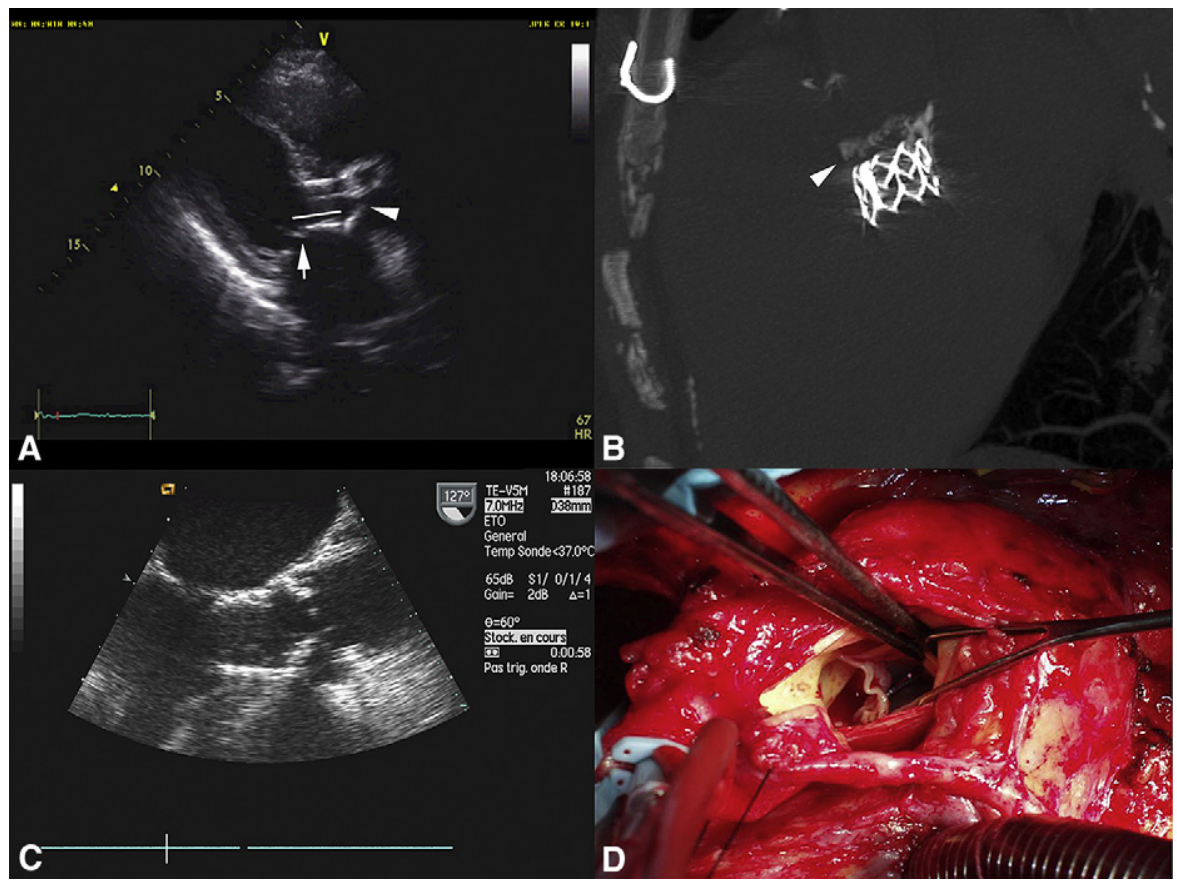

FIGURE 2. Transthoracic echocardiography (A) and computed tomographic scan (B) showing migration of the prosthesis in the left ventricular outflow tract, hindering the anterior mitral leaflet. Arrowhead indicates native aortic valve; arrow shows the inferior limit of the prosthesis; bar depicts the position of the anterior mitral leaflet. Transesophageal echocardiography $(\mathrm{C})$ and operative view $(\mathrm{D})$ confirming the migration of the prosthesis below the native aortic valve, which presents only moderate calcifications. 
of a thorough predischarge checkup after transcatheter aortic valve implantation even in symptom-free patients.

\section{References}

1. Himbert D, Descoutures F, Al-Attar N, Iung B, Ducrocq G, Détaint D, et al. Results of transfemoral or transapical aortic valve implantation following a uniform assessment in high-risk patients with aortic stenosis. J Am Coll Cardiol. 2009;54: 303-11.
2. Attias D, Himbert D, Hvass U, Vahanian A. "Valve-in-valve" implantation in a patient with stentless bioprosthesis and severe intraprosthetic aortic regurgitation. $J$ Thorac Cardiovasc Surg. 2009;138:1020-2.

3. Clavel MA, Dumont E, Pibarot P, Doyle D, De Larochellière R, Villeneuve $\mathbf{J}$, et al. Severe valvular regurgitation and late prosthesis embolization after percutaneous aortic valve implantation. Ann Thorac Surg. 2009; $87: 618-21$.

4. Maroto LC, Rodriguez JE, Cobiella J, Silva J. Delayed dislocation of a transapically implanted aortic bioprosthesis. Eur J Cardiothorac Surg. 2009;36: 935-7.

\title{
Pulmonary vein thrombosis after video-assisted thoracoscopic left upper lobectomy
}

\author{
Kazuto Ohtaka, MD, Yasuhiro Hida, MD, PhD, Kichizo Kaga, MD, PhD, Yasuaki Iimura, MD, PhD, \\ Nobuyuki Shiina, MD, Jun Muto, MD, and Satoshi Hirano, MD, PhD, Sapporo, Japan
}

Thrombus in the stump of the pulmonary vein (PV) after lung resection is a rare but lethal complication. Only 3 case reports have described radiographically detected thrombus in the stump of the PV. ${ }^{1-3}$ Thrombus in the systemic circulation can result in infarction of the brain, kidneys, and spleen. We describe 3 patients with thrombus in the stump of the PV after video-assisted thoracoscopic left upper lobectomy.

\section{CASE REPORTS \\ Patient 1}

A shadow was evident in the left upper lung field in the routine screening chest x-ray of a 64-year-old woman who was a nonsmoker with a medical history of chronic atrial fibrillation. Chest computed tomography (CT) showed a mass $31 \mathrm{~mm}$ in diameter in the left upper lobe. A transbronchial lung biopsy (TBLB) demonstrated adenocarcinoma. She underwent left upper lobectomy with systematic lymph node dissection using video-assisted thoracoscopic surgery. The left superior pulmonary vein (LSPV) was divided using a linear stapler at the point where it branched to the superior segment, and the branch to the lingular segment was ligated and divided. The

\footnotetext{
From the Division of Cancer Medicine, Department of Surgical Oncology, Hokkaido University Graduate School of Medicine, Sapporo, Japan.

Disclosures: Authors have nothing to disclose with regard to commercial support.

Received for publication July 11, 2011; revisions received Aug 8, 2011; accepted for publication Sept 21, 2011; available ahead of print Oct 19, 2011.

Address for reprints: Yasuhiro Hida, MD, PhD, Department of Surgical Oncology, Division of Cancer Medicine, Hokkaido University Graduate School of Medicine, North 15, West 7, Kita-ku, Sapporo 060-8638, Japan (E-mail: yhida@med. hokudai.ac.jp).

J Thorac Cardiovasc Surg 2012;143:e3-5

$0022-5223 / \$ 36.00$

Copyright (c) 2012 by The American Association for Thoracic Surgery doi:10.1016/j.jtcvs.2011.09.025
}

postoperative course was uncomplicated. She was prescribed oral tegafur/uracil as adjuvant chemotherapy and followed up every 6 months. Enhanced CT showed a thrombus in the stump of the LSPV 19 months postoperatively (Figure 1, A). Anticoagulant therapy was immediately started, and CT 24 months postoperatively showed that the thrombus had disappeared.

\section{Patient 2}

A 66-year-old man, who had continuously smoked 35 cigarettes per day for 30 years, underwent surgery and radiotherapy for maxillary cancer in 1994, surgery for oropharyngeal cancer in September 2002, and surgery for tongue cancer in December 2002. Chest CT in September 2008 showed a mass $35 \mathrm{~mm}$ in diameter. Adenocarcinoma was confirmed by TBLB. He was treated by videoassisted thoracoscopic left upper lobectomy with systematic lymph node dissection. The LSPV was divided using a linear stapler. The postoperative course was uncomplicated. He was prescribed oral tegafur/uracil as adjuvant chemotherapy and followed up using enhanced CT every 6 months. Enhanced CT showed a thrombus in the stump of the LSPV 18 months postoperatively (Figure 1, B), but cerebral infarction developed on the same day. Brain herniation, pneumonia, and acute renal failure followed, and he died 19 months postoperatively.

\section{Patient 3}

A 53-year-old woman, who was a nonsmoker with no medical history, underwent right nephrectomy to treat right renal cell carcinoma in March 2005. Follow-up chest CT in March 2010 showed a nodule $14 \mathrm{~mm}$ in diameter in the left upper lobe. Adenocarcinoma was confirmed by TBLB. She was treated by video-assisted thoracoscopic left upper lobectomy with systematic lymph node 